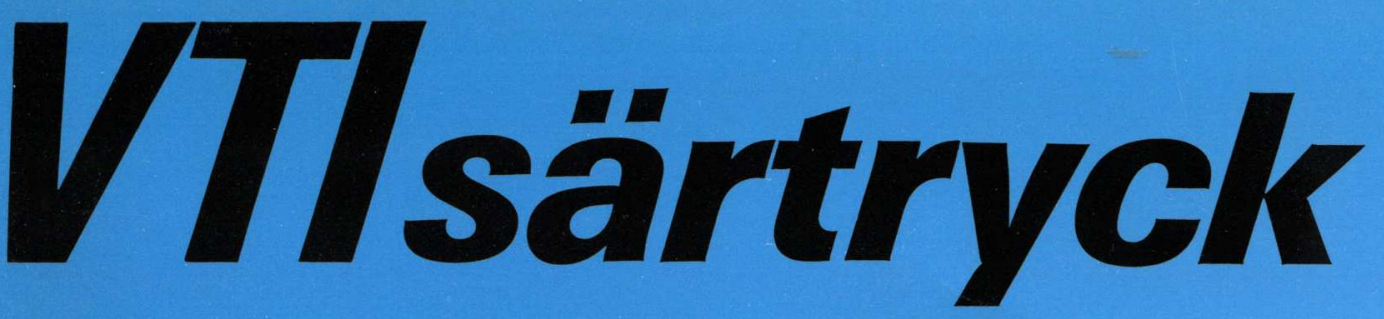

Heavy Duty Vehicle Dynamics Related to Braking, Steering and Tyres - Swedish Research and Proposals by VTI

Olle Nordström

Reprint from SAE Technical Paper Series, SP-801-Vehicle Dynamics Related to Braking and Steering, paper 892502, pp 43-57 (Truck and Bus Meeting and Exposition, Charlotte, North Carolina, November 6 - 9, 1989) 



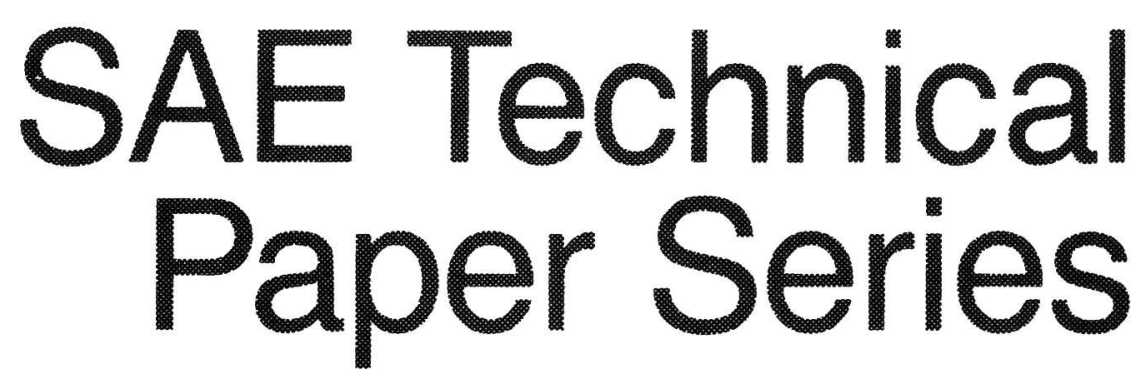

892502

\section{Heavy Duty Vehicle Dynamics Related to Braking, Steering and Tyres - Swedish Research and Proposals by VTI}

Swedish Road and Traffic Research Institute

Olle Nordström Linköping, Sweden

Reprinted from SP-801-Vehicle Dynamics

Related to Braking and Steering

Truck and Bus Meeting and Exposition Charlotte, North Carolina November 6-9, 1989 


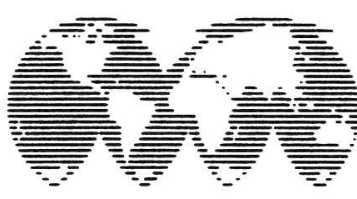

The papers included in this volume are abstracted and indexed in the SAE Global Mobility Database.

No part of this publication may be reproduced in any form, in an electronic retrieval system or otherwise, without the prior written permission of the publisher.

\section{ISSN 0148-7191}

Copyright 1989 Society of Automotive Engineers, Inc.

Positions and opinions advanced in this paper are those of the author(s) and not necessarily those of SAE. The author is solely responsible for the content of the paper. A process is available by which discussions will be printed with the paper if it is published in SAE Transactions. For permission to publish this paper in full or in part, contact the SAE Publications Division.
Persons wishing to submit papers to be considered for presentation or publication through SAE should send the manuscript or a 300 word abstract of a proposed manuscript to: Secretary, Engineering Activity Board, SAE. 


\title{
Heavy Duty Vehicle Dynamics Related to Braking, Steering and Tyres - Swedish Research and Proposals by VTI
}

\author{
Olle Nordström \\ Swedish Road and Traffic Research Institute \\ Linköping, Sweden
}

\section{ABSTRACT}

Research concerning heavy duty vehicle dynamics related to braking, steering and tyres has been conducted by the Swedish Road and Traffic Research Institute (VTI) for about 20 years. The aim has been to develop test procedures and propose minimum performance requirements primarily for vehicle combinations. This paper summarizes results concerning dynamic stability in a double lane change manouevre at constant speed, overturning stability, emergency antilock braking performance under winter conditions in terms of stability, steerability and braking performance during emergency braking in a tuxn on ice and during straight line braking on ice, split friction and transition from low to high friction. Hybrid simulation and a tyre tester are also described.

\section{THE SWEDISH ROAD AND TRAFFIC RESEARCH} INSTITUTE (VTI) is a governmental research organizatior dealing with research and testing concerning road building, traffic engineering, human factors, road vehicles and lately also some railway research.

The road vehicle research is mainly safety criented and deals with both crashworthiness and crash avoidance problems. Since about 20 years great emphasis has been laid on research concerning the dynamic performance of heavy vehicle combinations.

The great majority of Swedish heavy vehicle combinations consists of a truck and a full trailer with a permissible total length of $24 \mathrm{~m}$. This type of combinaticn as well as tractor and semitrailes. and truck and centre axle trailer. combinations has a speed limit of $70 \mathrm{~km} / \mathrm{h}$ (Figure 1 ).

Combinations with two trailers have a speed limit of $40 \mathrm{~km} / \mathrm{h}$ (Figure 2). Individual approvals for $70 \mathrm{~km} / \mathrm{h}$ can however be obtained if certain technical specifications are fulfilled. These restrictions are by Swedish industry transport research organizations (IVA TFK, Volvo) regarded as a major obstacle for an improvement of the road transport system in Sweden.

The VTI research has to a large degree been motivated by the actions of these organizations and the concern of the road safety authorities to ensure that the level of road safety is maintained or improved.

The research has primarily dealt with the following problem areas.

- the dynamic yaw stability and handling properties at constant speed

- the overturning stability

- stability, steerability and braking efficiency in braking manoeuvres

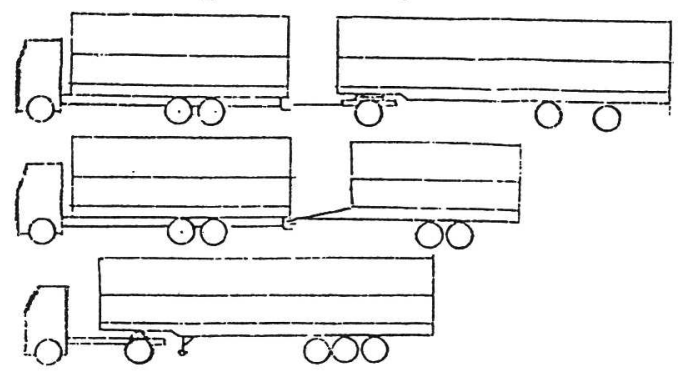

Figure 1 Vehicle combinations with $70 \mathrm{~km} / \mathrm{h}$ speed limit in Sweden
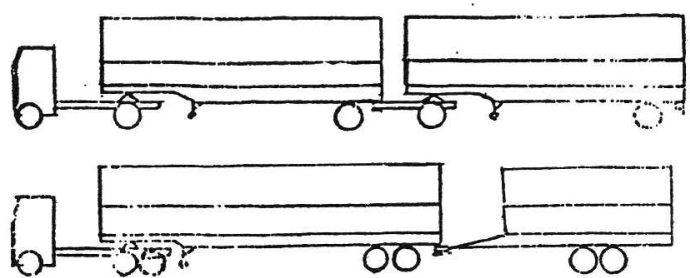

Figure 2 Vehicle combinations with $40 \mathrm{~km} / \mathrm{h}$ speed limit in Sweden except after special approval 
Special interest has been taken in evaluating the performance on ice covered roads.

The aim of this paper is to review this research and give the present VTI position concerning desirable performance and methods of testing and legislative enforcement.

\section{DYNAMIC STABILITY AT CONSTANT SPEED}

1970 - 72 full scale experiments and computer simulations were made with combinations with up to three articulations. The dynamic stability was tested by means of a double lane change manoeuvre (Figure 3 ). This maneuvre was chosen as it was regarded as the most severe in real traffic.

In the simulation the motor vehicle was steered by an automatic controller called DAVIS in such a way that the lateral acceleration of the c.g. followed a prescribed sinusoidal curve with $1.75 \mathrm{~m} / \mathrm{s}^{2}$ as maximum value.

As a result of these studies VTI proposed that minimum performance requirements in this manoeuvre should be set for heavy vehicle combinations $(1,2,3)^{*}$. These were the following:

- rearward amplification of side slip angles should not exceed 2 related to the mean value of the tractor rear axles

- the side slip angles must not exceed 150 $\operatorname{mrad}\left(8,6^{\circ}\right)$

- the oscillatory damping must be such that all side slip angles are less than $20 \mathrm{mrad}$ $\left(1,15^{\circ}\right)$ when the front axle is 75 metres away from the entrance of the exit corridor

- the overturning risk must be smaller than 1. (No wheel lift must occur)

- the lateral axle deviation must stay within certain limits ensuring that the vehicle combination stays on a $7 \mathrm{~m}$ wide road

In the period 1972 to 1981 further development of the simulation program was made (4) and new simulation studies were made including about 400 heavy vehicle combinations $(7,8,9)$.

The simulation studies that have been made indicate that few articulation points are desirable. At the same time other parameters were just as important from stability point of view. It is desirable to have

speed $70 \mathrm{~km} / \mathrm{h} \quad \max$ load max $\mathrm{c} g$ height

Figure 3 VTI double lane change test. Full scale configuration

${ }^{*}$ Numbers in parentheses designate references at the end of the paper
- a short distance between dolly pintle hook and the first semitrailer rear axle (or load centre of the rear axles in the case of multiple axles)

- long wheelbase on the trailers

- high tyre cornering stiffness which increases proportional to the load

- a low centre of gravity height

- high roll stiffness

- optimized roll or side force steer on the trailer axles as it has a significant effect

These findings agree with later studies nade at UMTRI in Michigan USA and in

Australia, Canada and England and the Federal Republic of Germany.

In 1981 a final report (10) was published. The recommendations in the report were basically the same as 1972 but in addition an approval system based on simulation results was outlined in more detail.

In 1984 the test procedure was used in full scale experiments on ice in comparative testing (13). The results indicated that suitably designed A-train type (Figure 4) double combinations could perform as well as or slightly better than a typical Swedish truck and full trailer combination in the terms of maximum speed without exceeding the track limitations. The truck full trailer combination which happens to have far from optimal dynamic performance could negotiate the track at $60 \mathrm{~km} / \mathrm{h}$ with trailer skid as limiting factor. The doubles could do 60 and $65 \mathrm{~km} / \mathrm{h}$. The lower performance was limited by understeer of the three axle tractor probably caused by too high friction in the fifth wheel turntable. The doubles were also tested with the yaw motion of the dolly relative to the first semitrailer eliminated.
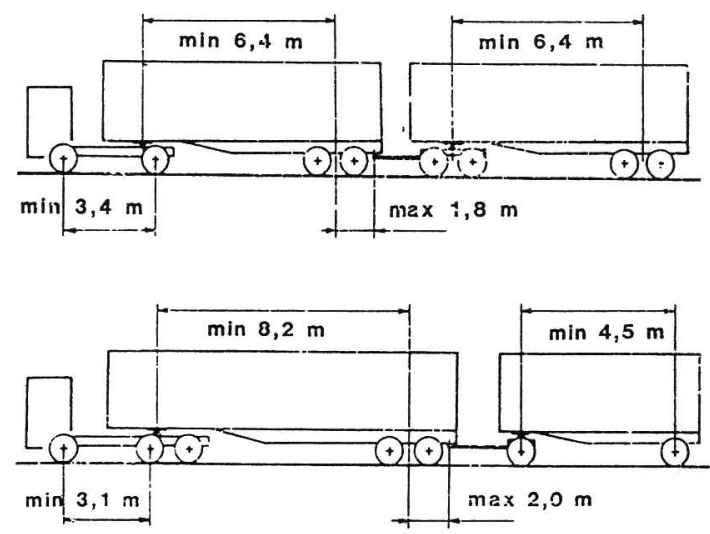

Figure 4 Recommended A-train configuration 1984 
This prevention of dolly jackknife did however not improve the lane change performance in terms of maximum speed.

Based on these tests and other considerations it was decided to give provisional permits for double combinations of the tested configurations or with more favourable design to be driven at speeds up to $70 \mathrm{~km} / \mathrm{h}$. Special requirements were also set for the brakes that had to be equipped with load sensing valves and/or an antilock system.

In 1986 and 1988 further lane change tests on ice were made with two special double combinations in order to have them approved for $70 \mathrm{~km} / \mathrm{h}$. The first combination had a yaw restrained centre axle trailer as second trailer (Figure 7, vehicle No. 13). The other combination was a conventional A-train with a short wheelbase three axle tractor where the non driven middle axle was tested steered and rigid. The test results were regarded as successful and were very similar to those obtained in 1984 i.e. about $65 \mathrm{~km} / \mathrm{h}$ limit speed. In these tests a single three axle truck was used as a reference. This vehicle performed marginally better. The limiting factor for the double combinations was trailer swing of the rearmost trailer. In the 1988 the yaw angle velocity rearward amplification was measured to be 1.6 at the rearmost trailer. No clear preference concerning steered or rigid tractor middle axle was found in this test.

In 1989 it has been proposed that double combinations should be approved for $70 \mathrm{~km}$ speed limit on a self zertification basis if they fulfilled certain performance demands. The vehicles would have to be equipped with ECE/EEC approved antilock brake systems.

The dynamic stability and steerability would be approved by means of a computer simulation of the double lane change developed by VTI. A more user friendly version of the program is planned to be developed for this purpose.

The performance requirements are somewhat changed compared with those originally proposed in 1972 in order to allow a simpler practical validation of the simulation test results if needed.

- The maximum allowed rearward amplification is still 2 but the reference variable has been changed to yaw velocity instead of side slip angle

- The limitation of lateral axle deviation is unchanged

- Also as before the overturning risk must be lower than 1 . This means that no wheel lift must occur.

Tyre cornering stiffness characteristics have an important influence on the simulation results. These characteristics vary with tyre type but also with road surface and inflation pressure.
In order to safeguard for these variations the simulations are to be made with reference tyre data which represent the lower limit of what can be expected on a wet asphalt or concrete road in normal condition. Presently used values of cornering stiffness are however higher than those used in the studies earlier presented by VTI and based on more recent measurements.

The double combination with best stability performance is expected to be of the so called B-train concept with only two articulation points where the second semitrailer is coupled directly to a fifth wheel at the rear end of the first semitrailer. It is however still important to keep the axle load centre of the first semitrailer close to the fifth wheel for the second semitrailer.

In Sweden several applications have been made for approval of combinations consisting of a tractor, a semitrailer and a centre axle trailer. Unlike the typical B-train rear semitrailer where the load is placed between the axles the centre axle trailer has a considerable load platform length behind the axle centre. On such a trailer it is possible to get the centre of gravity behind the trailer axle(s) which would give a tendency to oscillatory instability above a critical speed which could very well be within the operating speed. The experience with this kind of combination seems to be very small and no literature on the subject has been found.

\section{OVERTURNING STABILITY}

Compared to a passenger car the overturning stability of a loaded heavy duty vehicle is very low. The most critical cases are when the cargo density is such that a vehicle height of $4 \mathrm{~m}$ or even more can be utilized. From safety point of view a high overturning limit is obviously desirable. Against this stands the desire to be able to carry the largest possible load volume and weight. In Sweden the maximum combination length is $24 \mathrm{~m}$ and the maximum weight is $51400 \mathrm{~kg}$. This is longer and heavier than in any other European country but the load per metre vehicle length is lower and allows for a lower c.g. height.

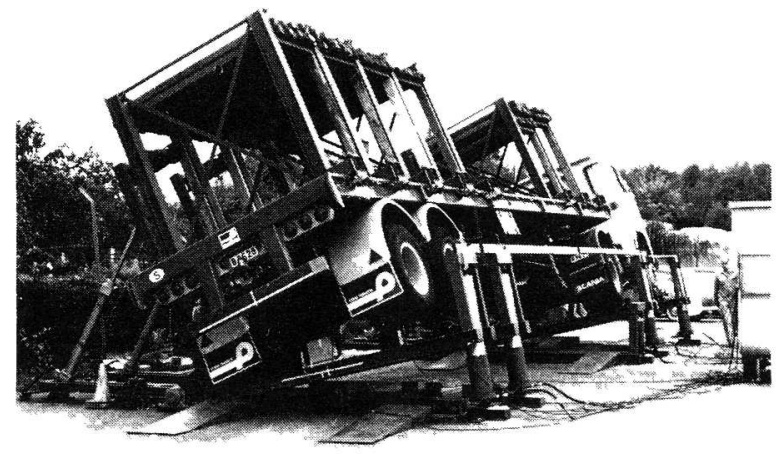

Figure 5 Hydraulic tilting device 
After full scale static tests of a number of representative Swedish trucks and trailers on a hydraulic tilting device (Figure 5), VTI in 1972 proposed a static overturning limit of $4 \mathrm{~m} / \mathrm{s}^{2}$.

Further studies were considered necessary and were also carried out but did not change the new recommendation given in 1981 (10). Since then investigators in USA, Australia and Canada have come to similar conclusions.

The effects of sloshing in partly filled road tankers have also been investigated by VTI $(5,6)$. Scale 1:10 model tanks of different shapes with and without longitudinal baffles were subjected to lateral motion controlled by a computer program.

The liquid forces and accelerations were measured and used as feed back input to the program, which simulated a double lane change manoeuvre and sinusoidal motions with varying frequencies (Figure 6). With 508 load volume it was found that the increase in overturning risk compared to a rigid load could be up to somewhat more than two times. Tests with different numbers and shapes of longitudinal baffles showed that three vertical baffles increase the resonance frequency well above the region that can be expected in the vehicle.

Still no regulations concerning overturning stability exist in Sweden. However the proposal concerning a simulated lane change test incorporat.es a maximum allowed c.g. height, determined by the manufacturer, for the different units in the combination. By definition the tractor will be subjected to a maximum lateral acceleration of 1.75 $\mathrm{m} / \mathrm{s}^{2}$ in the lane change. With an assumed rearward amplification of 2 the rearmost trailer could then be exposed to $3.5 \mathrm{~m} / \mathrm{s}^{2}$ which must not result in a wheel lift.
The proposed regulation also incorporates a requirement to state the static overturning stability of the laden trailers.

A recent decision to increase the maximum combination weight to $60000 \mathrm{~kg}$ makes c.g. height limiting regulations still more important.

\section{STABILITY, STEERABILITY AND BRAKING EFFICIENCY IN BRAKING MANOEUVRES}

In order to ensure desirable accident avoidance performance it is necessary that the braking system of a heavy duty vehicle and especially of a heavy cuty vehicle combination can be applied with full control force and still maintain stability and steerability. At the same time a high utilization of available road friction must be obtained. This is valid for all load and friction conditions.

Conventional braking systems without load sensing valves for heiry vehicles will tend to give wheel locking at emergency braking on low friction and with the vehicle unladen also on high friction. These problems can be reduced but not eliminated by load sensing valves.

In Sweden these valves were once made mandatory for heavy vehicles but were not successful. The functional problems especially on trailers were so great that the requirement was abandoned. Despite improved technology load sensing valves have still not gained any popularity on a voluntary basis except perhaps for airsprung vehicles.

The braking characteristics of heavy vehicle combinations in Denmark, Finland, Norway and Sweden were investigated by road and laboratory brake tests on in total 400 combinations (21) randomly selected from the

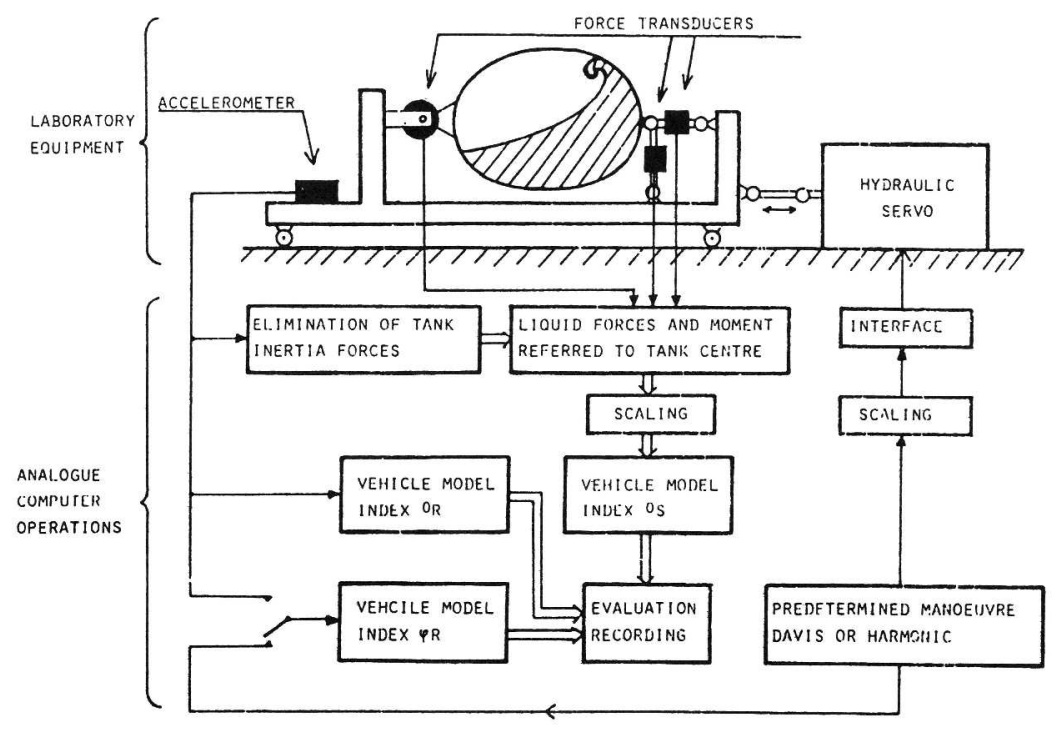

Figure 6 Scale model simulation of lateral sloshing in road tankers (from VTI Report No 82A) 
traffic on suitable roads.

The theoretical advantage of load sensing valves could not be confirmed in this study. On the contrary the results indicate that maladjustments still is a significant problem that reduces the braking efficiency at full load and still gives wheel locking at almost the same deceleration as for vehicles without these devices. The trailers were in general underbraked relative to the truck or tractor especially at high pressures.

Poor brake adjustment resulting in long pushrod stroke was one of the reasons for poor braking efficiency despite mandatory automatic adjustment. Very short strokes were also associated with a reduction in braking efficiency. In Sweden ligtly laden vehicles showed significantly smaller braking force/pressure ratio than fully laden vehicles. As these vehicles had no load sensing valves the results could indicate glazing effects due to the low brake forces used in the unladen condition which then recovered when in the laden condition after a transition period. There is however a possibility of bias if drivers with laden vehicles with poor brakes or overload were warned by their colleagues and changed their route. The VTI conclusion is that closed loop brake control systems with a warning signal to the driver in case of malfunction is an important part of the solution to the present brake system problems.

An antilock brake system is an example of such a system designed to prevent wheel locking due to overbraking. This solves the problems of stability and steerability in an emergency braking situation. Normally also the braking performance is improved. Under non locking condition these systems are however, inactive. A system for automatic brake force adaptation between a truck and a full trailer has been introduced on the Swedish market by the Swedish company VBG under the name Bromsgyro. This system is fully contained on the truck and consists of a coupling force sensor, a variable pressure reduction valve driven by an electric motor and a controller. A display shows the driver the degree of pressure reduction and whether the trailer is over-or underbraked in relation to the truck.

SWEDISH PROPOSAL FOR COMPLEMENTARY WINTER SERVICE REQUIREMENTS TO BE ADDED TO THE NEW ECE REQUIREMENTS FOR ANTILOCK BRAKING SYSTEMS (ABS)

In Sweden icy roads can be expected about six months of the year. Safe braking under these conditions is a considerable problem.

Antilock braking systems with good performance on ice are therefore expected to give a significant reduction in traffic accidents where braking is involved.

The United Nations Economic Commission for Europe (ECE) has developed a large number of international road vehicle regulations.
The ECE Regulation No 13 adresses brakes and contains since 1979 an annex concerning requirements on antilock brakes. A revised version became effective in 1987 . The same rules have also been adopted by the European Economic Community (EEC) in 1986.

Sweden took active part in the establishment of the revised version of the ECEantilock regulation but has still not adopted it in its national legislation. The author of this paper represented Sweden in this work and has also been responsible for several studies $(11,12,13,15,17,18,19)$ concerning antilock system performance under winter conditions carried out by the Swedish Road and Traffic Research Institute(VTI).

The VTI investigations have been made with heavy vehicles and vehicle combinations from about 5000 to more than $65000 \mathrm{~kg}$ as well as for a number of passenger cars as shown in Figure 7. Five different antilock systems for heavy vehicles and three for passenger cars have been tested.

Based on these investigations winter service test methods and requirements are proposed to be added to the ECE/EEC-regulations. These are:

- J-turn braking test on ice

- Split friction test with very low friction on one side

- Straight line braking on ice

- Transition from low friction to high friction surface

A hybrid laboratory test is envisaged as 3 future possibility of checking these performances for electronic antilock systems. In this test the vehicle is stationary and connected to a computer.

In the following, these winter test procedures and requirements are presented.

\section{J-TURN TEST ON ICE}

GENERAL - Vehicles with antilock system also on the steered wheels will if they meet the requirements of a straight braking efficiency test certainly possess some degree of steerability. On very low friction surfaces a bad antilock system may, however, give either very poor stability or very poor steerability, due to high slip levels and poor slip distribution between front and rear axles. In both cases the expected safety benefits will not be obtained and in the unstable case it might even be more dangerous to use such an antilock system than a conventional brake system or an antilock system acting only on the rear wheels. It is therefore essential to test the steering qualities during emergency braking on low friction in a special test.

This is also important for trailers as the steerability and stability of a vehicle 
combination also deperids on the performance of the trailer.

A driver controlled J-turn test is proposed. Open loop tests were found to be too severe for heavy vhicles which are normally somewhat oversteered during antilock braking A J-turn test is less space demanding than a steady state circular test

TEST SPECIFICATION - The driver controlled $\mathrm{J}$-turn test on ice (Figure 8) has the following specifications.

- The track surface shall consist of ice with a lateral friction corresponding to a maximum cornering speed between 40 and 60 $\mathrm{km} / \mathrm{h}$

- The test track shall have a $30 \mathrm{~m}$ long entrance corridor, $0.5 \mathrm{~m}$ wider than the vehicle, followed by a $100 \mathrm{~m}$ radius circular track $1.5 \mathrm{~m}$ wider than the vehicle

The test procedure comprises:

- determination of maximum cornering speed without braking $\left(V_{M}\right)$

- determination of the maximum speed $\left(V_{0}\right)$ and the deceleration $\left(a_{x}\right)$ at which the vehicle can be braked with ABS and full pedal force
Optional reference tests are:

- locked wheel straight line braking from 40 $\mathrm{km} / \mathrm{h}$ on the same surface

- determination of an ECE-type maximum constant deceleration in the turn without wheel locking from 75 of of $V_{M}$ based on front axle braking

PERFORMANCE REQUIREMENT - The following stability/steerability performance is proposed:

- to stay within the track boundaries with all parts of the tyre treads

- not to exceed a steering correction of +1 $180^{\circ}$

- to have a stability/steerability factor $E_{S}$ not less than 0.64 where $E_{S}=\left(V_{0} / V_{M}\right)^{2}$, i.e. successful braking from $80 \%$ of the maximum cornering speed

- the braking efficiency $E_{B Y}=a_{x} / a_{y}$, with the maximum cornering acceleration $\left(a_{y}\right)$ as reference, is proposed to be at least 0.5

- the braking efficiency $E_{B E}=a_{x} / a_{E C E}$, based on the maximum deceleration, with front brakes only, to be at least 0.75

\begin{tabular}{|c|c|c|c|}
\hline TEST VEHICLES & $\underset{K G}{\text { TEST WEIGHT }}$ & TEST VEHICLES & $\underset{\mathrm{KG}}{\text { TEST WEIGHT }}$ \\
\hline (1) & $\begin{array}{c}6500-13000 \\
9600-22700 \\
15800 \\
10800 \\
12000-33000 \\
16300 \\
17000-51400 \\
13000-28500 \\
15000-36400 \\
20500-51400 \\
20000-51400 \\
22000-66400 \\
50900\end{array}$ & (14 & $\begin{array}{l}1215-1520 \\
1600-1920 \\
1580 \\
1580-1840 \\
1640-1810\end{array}$ \\
\hline
\end{tabular}

Figure 7 Test vehicles 
- the braking efficiency $E_{B E}=a_{x} / a_{E C E}$, based on the maximum deceleration without wheel

locking, to be at least 0.75

The test is also proposed for trailers which shall be tested in combination with a worst case approved antilock motor vehicle. TEST RESULTS - Results from the closed loop J-turn test are presented in Figure 9 and 10 .

Figure 9 illustrates the relationship between the stability/steerability factor $E_{S}$ and the braking efficiency $E_{B Y}$ for passenger cars and heavy duty vehicles.

Figure 10 presents the relationship between $E_{S}$ and $E_{B L}$ also with separate results for passenger cars and heavy duty vehicles.

The diagrams show no correlation between the stability/steerability factor and the braking efficiency. Results from tests with increasing initial speed have, depending on the tyre equipment, given both increasing and decreasing braking efficiency. From the diagrams can be seen that if all results were to be accepted. $E_{S}$ should be at least 0.5 instead of the proposed at least 0.64 . The latter choice is based on the opinion that this value is more representative for the state of the art. The vehicles that did not meet this requirement should be improved.

SPLIT FRICTION TEST WITH VERY LOW FRICTION ON ONE SIDE

GENERAL - In order to reduce cost and to reduce yaw moment and torque effects in the steering when braking on a surface with different friction for the left and right hand side wheels (split friction surface) antilock systems have been made with only one regulator per axle that adjusts the brake force on the axle to the lowest friction. This is called "select low" control. When the friction is very low as for instance on ice this can result in extremely long braking distances compared to individual wheel braking. This is shown in Figure 11 which also illustrates that the present ECE/EEC regulation is not very efficient as well as the improvement achieved with a proposed change originating from WABCO.

TEST SPECIFICATION - The split friction test which is already part of the ECE/EECregulations is illustrated by Figure 12. The test track consists of two parallel tracks, one with a high friction $\mathrm{K} 1$ and the other with a low friction $\mathrm{K} 2$. The test is performed from an initial speed of $50 \mathrm{~km} / \mathrm{h}$ in three steps.

The two first steps give the values of $\mathrm{K} 1$ and $\mathrm{K} 2$ by means of maximum constant pedal force single axle braking without wheel locking. The third step gives the split friction braking ratio 23 . (Braking ratio = deceleration/9.81). The ECE/EEC performance requirements are:

- a maximum lateral displacement where no parts of the tyre treads cross the common track boundary

- a maximum steering correction of $120^{\circ}$ within the first two seconds and $240^{\circ}$ during the rest of the stop

- a minimum braking ratio $23=0.75(4 \mathrm{~K} 2+\mathrm{K} 1) / 5$ but not less than the low friction $\mathrm{K} 2$

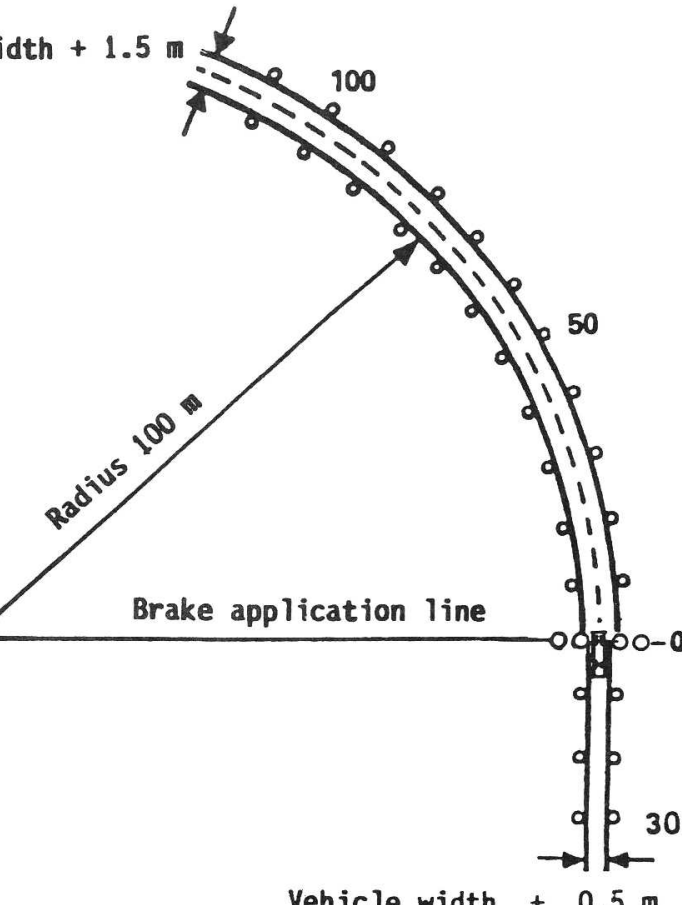

Figure 8 J-turn antilock braking test with driver control. Test track configuration 

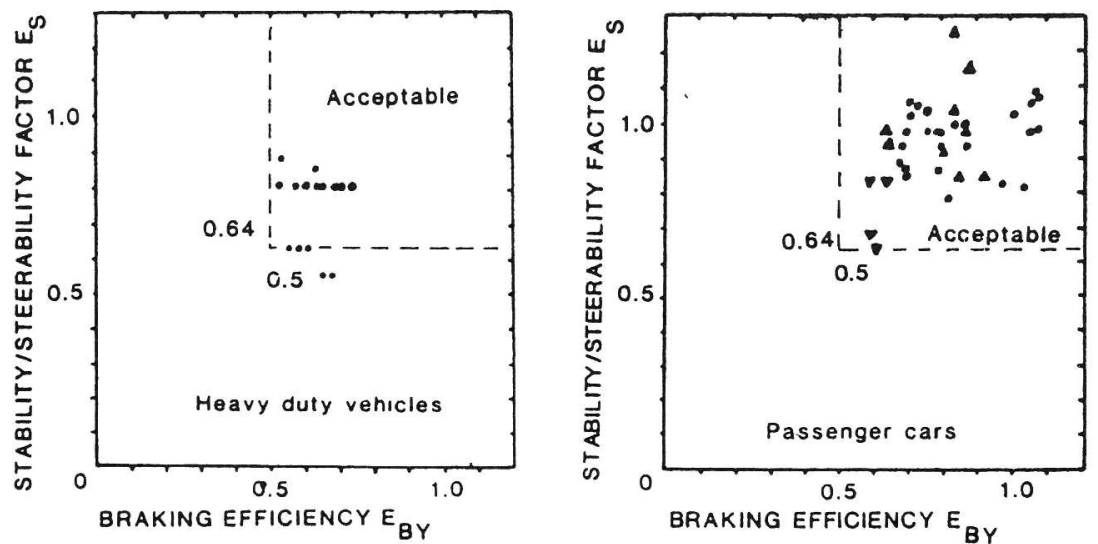

Figure 9 J-turn antilock braking test with driver control. Test results showing stability/steerability factor and braking efficiency $E_{B Y}$
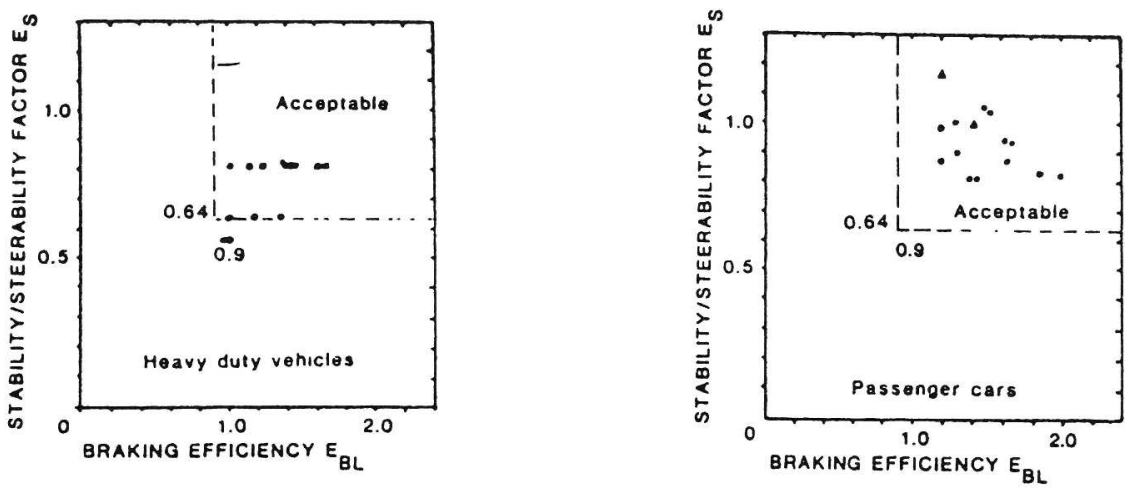

Figure 10 J-turn antilock braking test with driver control. Test results showing stability/steerability factor and braking efficiency $\mathrm{E}_{\mathrm{BL}}$

The last requirement in combination with an allowed ratio $K 2 / K 1$ as high as 0.5 is a major weakness in the regulation as it allows an efficient "select low" system to pass the test.

PROPOSAL FOR WINTER CONDITION REQUIREMENTS - As a realistic compromise it is proposed that the braking efficiency formula should be based on the actually achieved antilock braking ratios $\mathrm{Z1}$ and $\mathrm{Z2}$ instead of $75 \%$ of $\mathrm{K} 1$ and $\mathrm{K} 2$ and become $\mathrm{Z} 3=0.2(4 \mathrm{Z} 2+$ $\mathrm{z1})$. It is also proposed that the ratio $\mathrm{z} 2 / \mathrm{z} 1$ must not exceed 0.4 and $Z 2$ not exceed 0.15 . It is furthermore proposed that the applicable requirements should also be met by trailers as they can represent a large part of the total combination mass.

The trailer should be tested together with a representative towing vehicle equipped with an approved antilock system. The braking efficiency of the trailer should also be tested by means of separate trailer braking. When $\mathrm{Z1}, \mathrm{Z2}$ and $\mathrm{Z3}$ are calculated, the rolling resistance of the towing vehicle can be set to 0.015 for driven wheels and 0.010 for non driven wheels.

TEST RESULTS - VTI has performed tests on split friction surfaces with ice as low

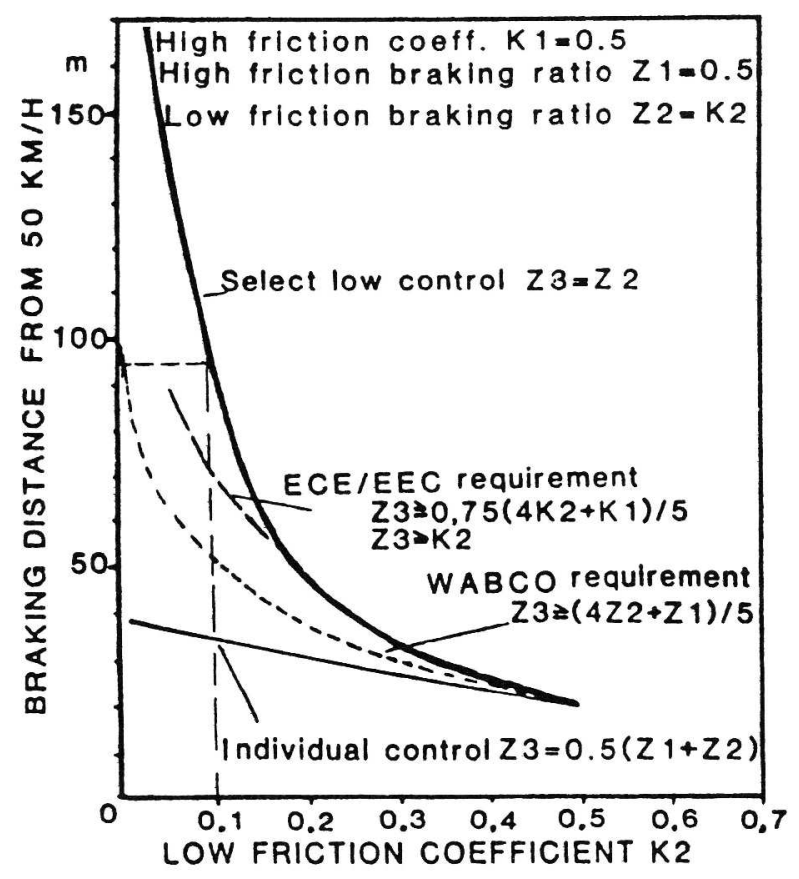

Figure 11 Split friction braking efficiency 
friction surface and sand bonded to the ice with water as high friction surface. The peak friction coefficients were about 0.1 and 0.6 and very similar locked wheel values. The tests took place during six winters from 1980 to 1988. The tested vehicles are shown in Figure 7. The systems represent different control strategies from "select low" to individual wheel control.

The test results are shown in Figure 13, 14 , and 15.

In Figure 13 the braking ratio $\mathrm{Z3}$ obtained in the split friction test is compared to the optimum braking ratio defined as $(\mathrm{Z} 1+\mathrm{Z} 2) / 2$. The braking ratios $\mathrm{Z} 1$ and $\mathrm{Z} 2$ are those obtained by antilock braking tests on the high and the low friction surfaces. It can be seen that the "select low" systems have a braking efficiency of only 27-45\% of the optimum braking compared to values between 67 and $90 \%$ for systems with higher degree of individual wheel control. In Figure 14 the braking ratio 23 is compared to the minimum required in the WABCO proposal. The tested vehicles with select low ABS did not meet this requirement.

In Figure 15 test results are compared to the ECE/EEC requirement. This is easier to meet than the WABCO proposal.

INFLUENCE OF TYPE OF TRAILER ABS - The ECE/EEC antilock regulations do not have a split friction test for trailers. This means that trailers with axle by axle "select low" type ABS may be used even when individual control $\mathrm{ABS}$ is required for the towing vehicle. VTI has carried out tests in 1988 (19) with a partly laden truck weighing 16400 $\mathrm{kg}$ and a fully laden trailer weighing 22600 $\mathrm{kg}$. The truck had an individual control ABS and the trailer had two versions of the same ABS. One version had "select low" control and the other individual control. Tests with the conventional system only were also made. On the split friction track the tests with the

ECE/EEC： K $1 \mathrm{~min}=0.5 \mathrm{~K} 2 \mathrm{max}=0.5 \mathrm{~K} 1$

$z 3 \geq 0.75(4 \times 2+K 1) 0.2 \quad Z 3 \geq K 2$

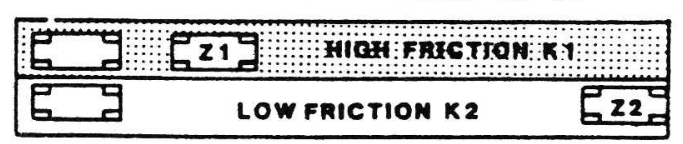

Vo.50 $\mathrm{km} / \mathrm{h}$
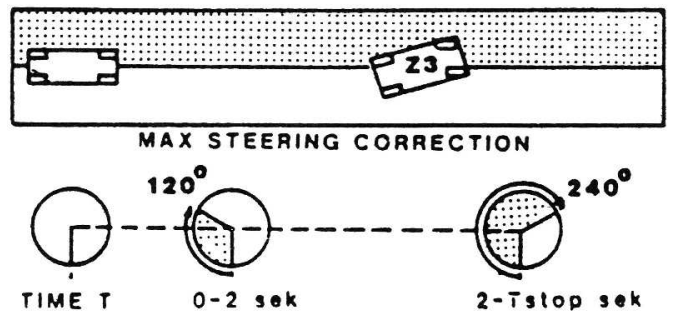

PROPOSEO NEW K2 $\mathrm{max}=0.40 \times 1$ OP

WINTER SERVICE $\quad 22 \mathrm{max}=0.40 \quad 21$

REQUIREMENTS $Z 320.2(4 Z 2+21)$

Figure 12 Split friction test procedure "select low" system gave $25 \%$ lower deceleration than with individual system and $40 \%$ less than with conventional brakes. This means 22-34 m longer braking distance from $50 \mathrm{~km} / \mathrm{h}$.

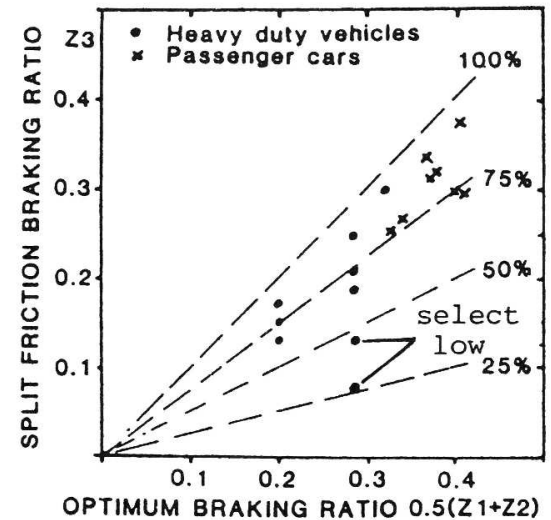

Figure 13 Split friction test results. Comparison with optimum performance

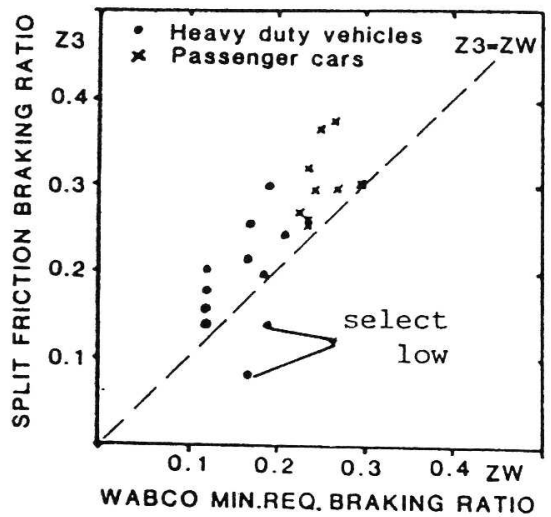

Figure 14 Split friction test results. Comparison with WABCO proposal

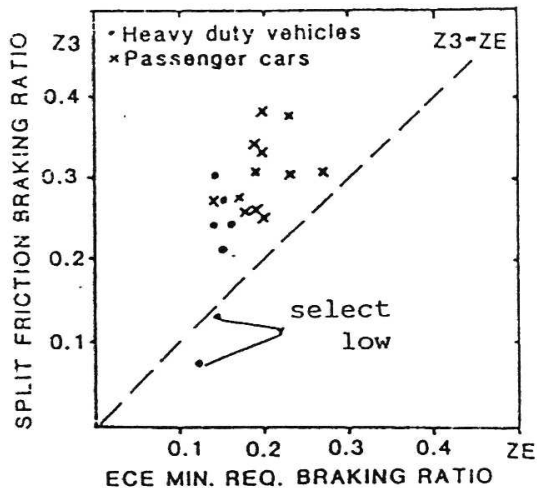

Figure 15 Split friction test results. Comparison ECE/EEC requirements

ABS-BRAKING COMPARED TO BEST DRIVER BRAKING - In 1984 split friction tests were also carried out in order to compare performance with and without antilock system. Four unladen heavy vehicle combinations (vehicles $6,7,10$ and 11 in Figure 7) were used. All but one (prototype system) were equipped with load sensing valves and WABCO antilock systems. Three drivers took part in the test 
but each combination was tested by only one driver.

The result of these tests was that the braking efficiency in most cases was 10-20\% higher with the normal braking system than with the antilock system in operation. The efficiency of the antilock systems was about 808 of $(z 1+z 2) / 2$. Both with and without antilock system it was possible to keep the vehicle within a $3.5 \mathrm{~m}$ lane. The steering and braking task was, however, more difficult without antilock system. The maximum steering angles were about $90^{\circ}$ with and $135^{\circ}$ without antilock system.

\section{STRAIGHT LINE BRAKING ON ICE}

GENERAL - Straight line braking on a homogeneous surface is the classic and basic way of testing the braking performance of vehicles. The ECE/EEC antilock braking regulations prescribe straight line low friction tests. The friction level is however allowed to be as high as 0.4. A test on ice is therefore regarded as a useful winter service approval requirement.

TESTS CARRIED OUT BY VTI - straight line antilock braking tests on ice have been made in comparison with

- locked wheel braking

- best driver control oraking

- peak friction measured with single axle braking according to ECE/EEC antilock regulation (see Figure 16 and 17) measured at 40 and $20 \mathrm{~km} / \mathrm{h}$. BV11 had a 4.00-8 tyre and BV12 a 5.60-15 PIARC "Europe" tyre both with rib tread, in accordance with ISO TR 8349 on friction measurement

Tests have been made from initial speeds ranging from 70 to $35 \mathrm{~km} / \mathrm{h}$ for trucks and trailers and, for passenger cars from 110 to $50 \mathrm{~km} / \mathrm{h}$.

Most of the tests have been done in the temperature range $-5^{\circ} \mathrm{C}$ to $-20^{\circ} \mathrm{C}$ but tests have also been made near $0^{\circ} \mathrm{C}$ and down to $-30^{\circ} \mathrm{C}$. Except in 1980 the tests have been made on ice roughened by the special multiwheel trailer with studded passenger car tyres shown in Figure 18. The treatment

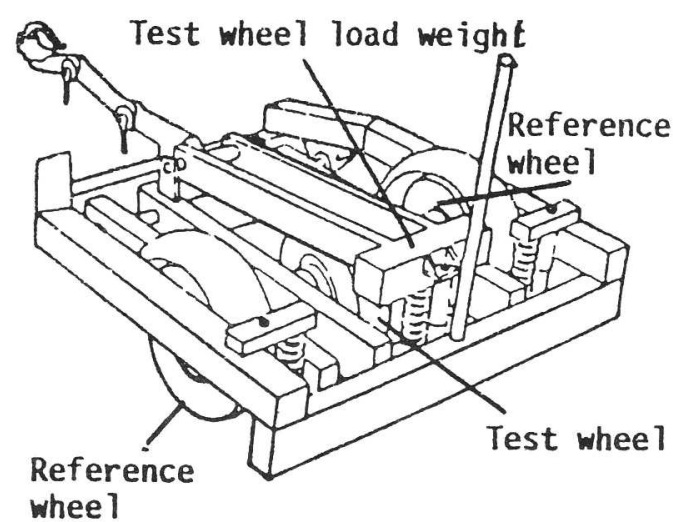

Figure 16 Friction test trailer BV11

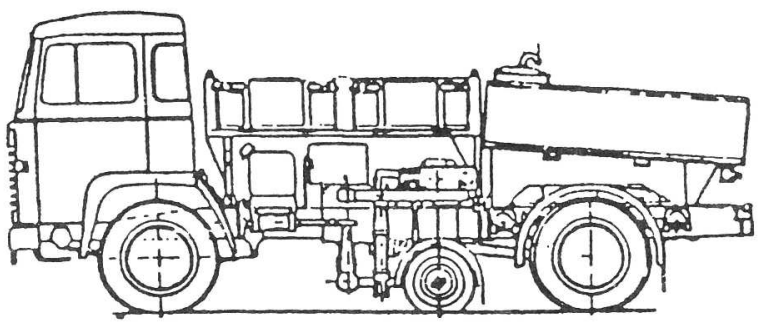

Figure 17 Friction test vehicle BV12

results in a somewhat higher and more uniform friction and reduces polishing effects which tend to lower the friction.

RESULTS - The results are summarized in Figure 19, 20, 21, 22 and 23.

From the figures can be seen that as a rule the braking efficiency with antilock systems is higher than with locked wheels and higher than best driver performances. In tests with laden and unladen vehicles the unladen vehicles tend to get higher deceleration but not necessarily higher braking efficiency based on peak value.

The $75 \%$ efficiency required by ECE/EEC regulations is not always met on ice by antilock systems for heavy vehicles. For the tested passenger cars with and without studs the efficiency is close to $100 \%$.

Longitudinal friction coefficients obtained with the reference tyres on friction test vehicles BV11 and BV12 according to the
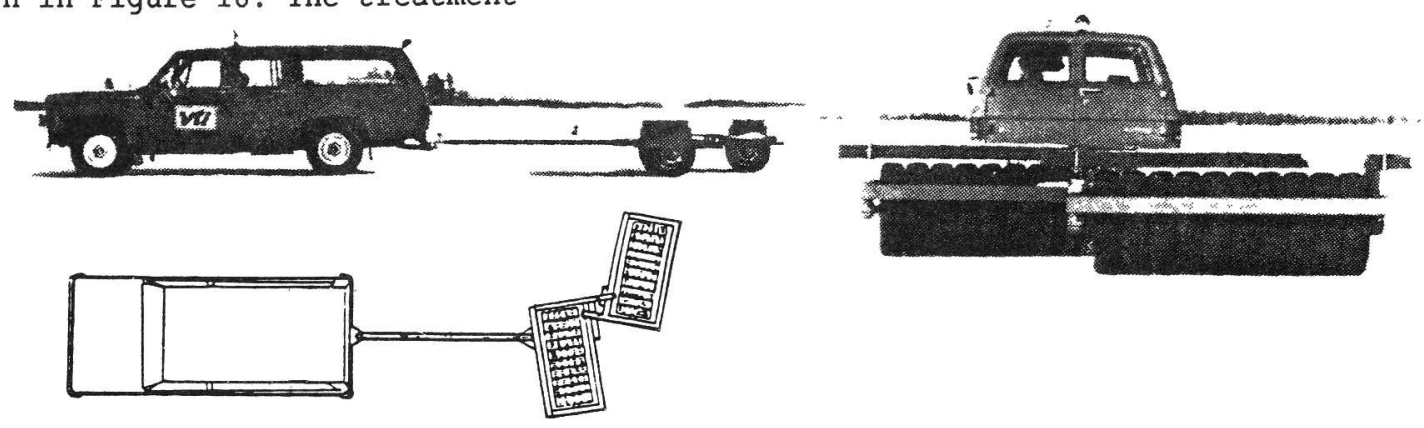

Figure 18 Multiwheel trailer with studded passenger car tyres for ice conditioning treatment 


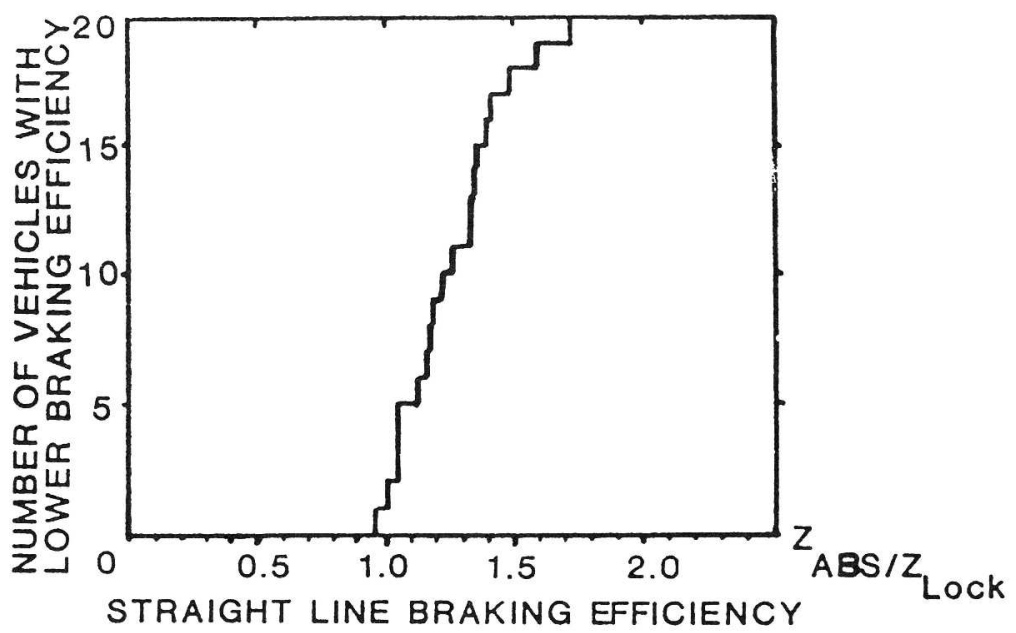

Figure 19 Straight line antilock braking efficiency in relation to locked wheel braking

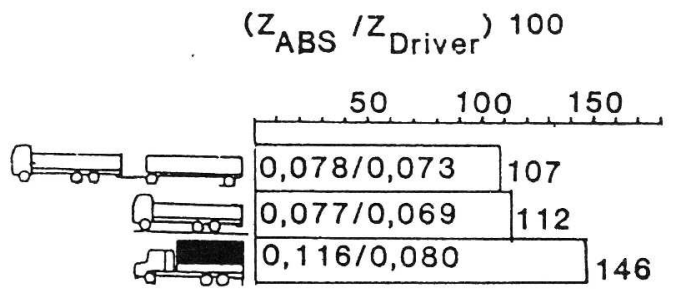

Figure 20 Straight line antilock braking test results. Comparison with test driver performance

\begin{tabular}{|c|c|c|c|}
\hline \multirow[b]{3}{*}{$\infty$} & \multicolumn{3}{|c|}{$\left(Z_{A B S} / K_{E C E}\right) 100$} \\
\hline & 50 & 100 & 150 \\
\hline & \multicolumn{2}{|l|}{$0,17 / 0,16$} & 105 \\
\hline & \multicolumn{2}{|l|}{$0,21 / 0,20$} & 106 \\
\hline \multirow[t]{2}{*}{ كैक्ष } & $0,16 / 0,17$ & \multicolumn{2}{|c|}{94} \\
\hline & \multicolumn{2}{|l|}{$0,11 / 0,09$} & \multirow[t]{2}{*}{123} \\
\hline El. & $0,17 / 0,23$ & 74 & \\
\hline Len & $0,15 / 0,14$ & & 107 \\
\hline
\end{tabular}

Figure 22 Straight line antilock braking test results. Comparison with ECE/EEC friction coefficient

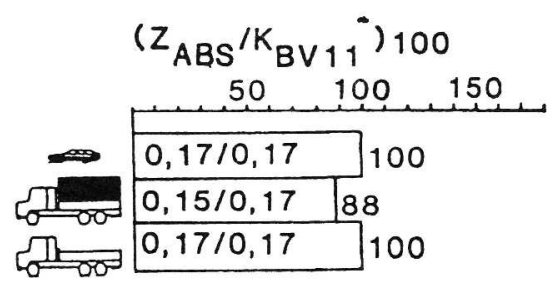

Figure 21 Straight line antilock braking test results with standard tyres. Comparison with friction test trailer BV11

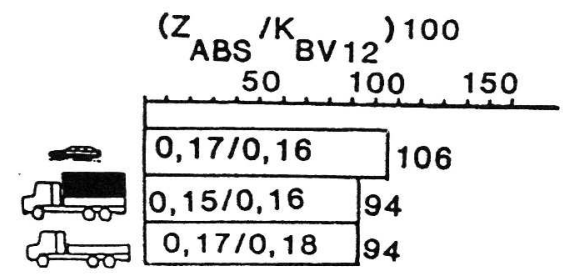

Figure 23 Straight line antilock braking test results with standard tyres. Comparison with friction test vehicle BV12 
constant slip method gave the same values as the peak friction coefficients obtained by single axle braking according to ECE Regulation 13 both for a truck and a passenger car with standard tyres $\left(\mu_{\mathrm{peak}}=0.17\right)$.

DISCUSSION - According to Annex 10 in ECE Regulation 13 normal brakes are allowed to have a braking efficiency of $50 \%$ at a friccion coefficient of 0.2 . It could therefore be debated if the efficiency requirements on antilock systems on ice should be as high as $75 \%$ of the peak friction coefficient. The test results indicate that $90 \%$ of the locked wheel friction could be a more suitable requirement. A locked wheel test is also the simplest and least expensive alternative. In order to avoid stability problems the locked wheel braking tests on ice are recommended to be done from an initial speed of $40 \mathrm{~km} / \mathrm{h}$.

PROPOSAL FOR A STRAIGHT AHEAD BRAKING TEST ON ICE - Based on the field test experience and theoretical considerations the following test is proposed.

Test surface-The test surface should be ice with a locked wheel friction of $0.1+/-$ 0.05 measured with the test vehicle itself or the friction test vehicle BV11 or equivalent equipment. Roughening of the ice by means of the special multi-wheel trailer according to Figure 18 is recommended. The air and ice surface temperature should be below $0^{\circ} \mathrm{C}$, preferably between -5 and $-15^{\circ} \mathrm{C}$.

Test speed-The initial speed should be 40 $\mathrm{km} / \mathrm{h}$ vehicles for tyres without studs and 50 $\mathrm{km} / \mathrm{h}$ for tyres with studs (additional test for passenger cars).

Braking tests-Locked wheel and antilock braking stops should be made with a pedal force that on high friction would give at least $5 \mathrm{~m} / \mathrm{s}^{2}$. The mean value of the results from at least three tests of each type should be used for the efficiency calculation. For each test the mean deceleration is calculated by the formula $a=5.56 / \mathrm{T} \mathrm{m} / \mathrm{s}^{2}$ where $\mathrm{T}$ is the time for $V=35 \mathrm{~km} / \mathrm{h}$ to $\mathrm{V}=15 \mathrm{~km} / \mathrm{h}$.

Minimum requirement on braking efficiency-

$\hat{a}_{\mathrm{ABS}} / \mathrm{a} \mathrm{L} \geq 0.9$ or $\left(\mathrm{z}_{\mathrm{ABS}} / \mathrm{z}_{\mathrm{LOCK}}\right) \geq 0.9$

$\hat{\mathrm{a}}_{\mathrm{ABS}}=$ Mean deceleration with the antilock system operating. $\mathrm{z}_{\mathrm{ABS}}=\mathrm{a}_{\mathrm{ABS}} / 9.81$

â $\quad=$ Mean deceleration with all wheels locked. $\mathrm{z}_{\text {LOCK }}=\hat{a}_{\mathrm{L}} / 9.81$

Trailer tests-Trailer tests should be made by braking only the trailer and correcting for the rolling resistance of the towing vehicle. The rolling resistance coefficient for nondriven wheels may be assumed to be 0.010 and for driven wheels 0.015 .

Alternative test method-Tests may also be performed according to the procedure prescribed by ECE/EEC regulations but on the same ice surface. It is considered as more difficult to carry out and meet the requirements of this test.
TRANSITION TEST FROM LOW TO HIGH FRICTION

GENERAL - When a vehicle with normal brakes is braked on very low friction and suddenly encounters a transition to a high friction surface the braking torque applied by the driver is immediately fully utilized up to the limit of adhesion for each axle as they pass on to the new surface.

In the same situation but braking a vehicle with an antilock system fully adapted to the low friction there is a risk that the pressure recovery might be very slow and result in an unacceptably long braking distance compared with a normal braking system. The new ECE/EEC antilock braking regulations therefore demand a test in this respect. The requirement on the high/low friction ratio is however only $2: 1$ which is low for winter service conditions.

TESTS CARRIED OUT BY VTI - Tests with one heavy duty truck antilock system on ice with very low friction resulted in pressure drops to near zero with recovery rates of not more than $3 \mathrm{bar} / \mathrm{sec}$ that could not be influenced by a sudden transition to high friction. This corresponds to about $1.5 \mathrm{~s}$ to reach $4.5 \mathrm{~m} / \mathrm{s}^{2}$ deceleration. Transition tests with other systems indicate that $0.7 \mathrm{~s}$ is a reasonable target from a technical point of view.

DISCUSSION - If the vehicle deceleration is measured the wheelbase has to be taken into account. At $50 \mathrm{~km} / \mathrm{h}$ an additional time delay of $0.7 \mathrm{~s}$ will cover all practical cases. A total deceleration transition time from $1.5 \mathrm{~m} / \mathrm{s}^{2}$ to $4.5 \mathrm{~m} / \mathrm{s}^{2}$ of $1.5 \mathrm{~s}$ for heavy duty vehicles and $1.0 \mathrm{~s}$ for passenger cars has been considered to be a reasonable requirement for winter service.

PROPOSED WINTER SERVICE TEST - The test shall be made with full brake application at a pressure that corresponds to a deceleration of at least $5 \mathrm{~m} / \mathrm{s}^{2}$ starting on a low friction surface which must not give the vehicle a higher deceleration than $1.5 \mathrm{~m} / \mathrm{s}^{2}$ with the antilock system in operation. The vehicle speed at the transition to high friction must not be less than $50 \mathrm{~km} / \mathrm{h}$. The high friction surface must allow an antilock braking deceleration of at least $4.5 \mathrm{~m} / \mathrm{s}^{2}$. This deceleration must be reached within $1.5 \mathrm{~s}$ for heavy duty vehicles and within $1.0 \mathrm{~s}$ for passenger cars. This time is measured from the front axle transition time.

\section{HYBRID LABORATORY TESTING - A FUTURE TYPE APPROVAL PROCEDURE?}

The practical difficulties are considerable both technically and economically in obtaining test tracks that give the desired friction characteristics and are large enough for safe high speed and cornering tests. In fact they are so severe that ECE/EEC regulations regard peak friction coefficients up to 0.4 at 40 to $50 \mathrm{~km} / \mathrm{h}$ as low and do not specify speed or slip characteristics of the 
tyre/road adhesion. Furthermore the problems connected with brake lining characteristics must not be forgotten.

For antilock systems with electric wheel speed signals these problems can be eliminated by real time computer simulation of the tyre/road characteristics, brake torque characteristics and vehicle motion dynamics including wheel speed sensor signals. The real vehicle that is to be tested is connected to the computer through an interface so that the simulated wheel speed signals are received by its antilock system controller and the wheel brake cylinder pressures measured by sensors on each wheel are fed back to the computer. During the test the vehicle is stationary in the laboratory with the engine running. The test engineer has only to apply the brakes after starting the computer program.

This technique has been used by VTI with promising results. At present it is possible to simulate:

- Straight braking on a homogeneous surface

- Straight braking on a split friction surface with steering corrections based on yaw motion

- Braking during steady state cornering with constant steer input

- J-turn braking with constant steer input applied at the same time as the brakes

- Braking on a surface with changing friction can also be simulated as the computer programme contains two tyre models for each wheel

Validation simulations have been made with a two axle truck with an unladen weight of $6500 \mathrm{~kg}$ and a laden weight of $13000 \mathrm{~kg}$. The vehicle was equipped with three different types of antilock systems. This vehicle was also used in the already mentioned tests on real ice tracks, split friction tracks as well as on high friction tracks. The following tests were used for the validation:

- Straight braking on homogeneous ice. Initial speed 10 and $20 \mathrm{~m} / \mathrm{s}$

- Straight braking on a split friction surface. Initial speed $10 \mathrm{~m} / \mathrm{s}$

- J-turn braking on ice with constant steering input corresponding to $100 \mathrm{~m}$ radius applied at the same time as the brakes. Initial speed $11 \mathrm{~m} / \mathrm{s}$

- Straight braking on a high friction surface with the peak friction coefficient 0.6 . Initial speed $20 \mathrm{~m} / \mathrm{s}$
In all the tests the ranking order in performance was the same in simulation and real test. The general characteristics in terms of deceleration, lateral acceleration and yaw behaviour over time were also quite well reproduced. This also applies to wheel speeds and brake pressures. Test were made both with identical tyre data on front and rear wheels and with somewhat reduced friction on the rear wheels. The best results were obtained in the latter case. This is in line with the fact that ice friction is reduced by the polishing effect of slipping tyres. In this case the front tyres polish the ice for the rear tyres. It is not believed that this method of testing can replace real world tests but it looks promising as a future complement for evaluating antilock system performance under conditions that are too difficult, expensive or dangerous to require in real type approval tests.

New soft-and hardware with a specially designed parallel processor system has recently been developed at VTI (20). The purpose was to reduce the computing time for wheel velocities and tyre forces from 5 to 1 $m s$ and at the same time allow for more wheels and more detailed tyre data. The system is however not yet incorporated in the hybrid ABS-simulation program.

\section{TRUCK TYRE TEST FACILITY}

Truck tyre data are very important for the simulation of heavy vehicle dynamics. In order to be able to obtain these data in a well controlled environment a truck tyre test facility with capacity for testing on ice has been built at VTI. The test wheel rig is stationary (Figure 24) and the test track is

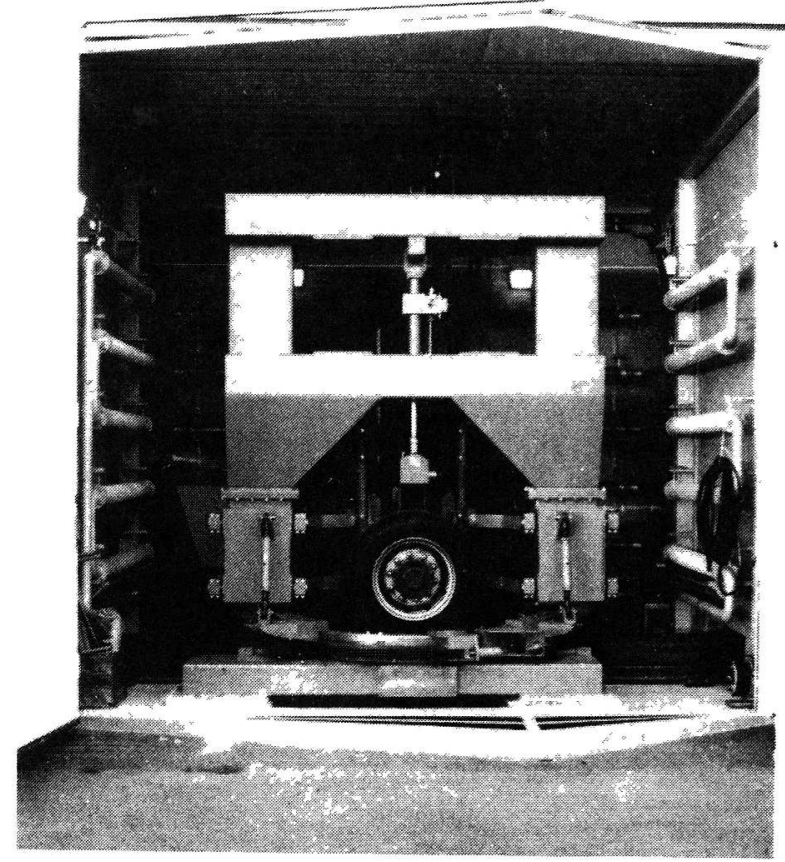

Figure 24 VTI truck tyre test facility 
a flat $50 \mathrm{~m}$ long moving steel beam. The maximum speed is at present about $10 \mathrm{~m} / \mathrm{s}$. Maximum wheel load is $10000 \mathrm{~kg}$ and lateral and longitudinal forces up to $70000 \mathrm{~N}$ can be measured. The side slip angle can be varied up to $90^{\circ}$ at up to $30^{\circ} / \mathrm{s}$. Ice temperatures down to $-20^{\circ} \mathrm{C}$ are possible. The facility became operational in May 1989 but has so far only been used for evaluating passenger car winter tyres. The first truck tyre measurements are planned for the autumn 1989.

\section{CONCLUSIONS}

The dynamics of heavy duty vehicles and especially heavy duty vehicle combinations has since a long time been regarded as an important area of research by VTI and will probably remain so for a long time.

The main investigation areas have been

- yaw stability and steerability at constant speed

- overturning stability with rigid and liquid load

- stability, steerability and braking efficiency during emergency braking

- tyre - road friction characteristics

The behaviour of heavy vehicle combinations under severe winter conditions has a high priority due to the climatic conditions in Sweden.

Road and computer simulation test methods and performance requirements have been investigated proposed for legislation use with the aim to promote safe vehicles on our roads.

\section{REFERENCES}

1. Nordström 0., Magnusson G. and Strandberg L. The Dynamic Stability of Heavy Vehicle Combinations. VTI Report No. 9, Part 1 and 2 . (In Swedish) VTI, Linköping, Sweden 1972

2. Nordström 0., Strandberg L. The Dynamic Stability of Heavy Vehicle Combinations. VTI Report No. 67A. VTI, Linköping, Sweden 1974

3. Strandberg L., Nordström O., Nordmark S. Safety Problems in Commercial Vehicle Handling. VTI Report No. 82A. VTI, Linköping, Sweden 1975

4. Nordmark S.

Computer Program for Digital Simulation of a Double Lane Change Manoeuvre with a Heavy Vehicle Combination. (In Swedish. Summary and list of figures in English) VTI Report No. 96. VTI, Linköping, Sweden 1976
5. Lidström $\mathrm{M}$.

Road Tanker Overturning - with and without longitudinal baffles. (In Swedish. Summary and list of figures in English) VTI Report No. 115. VTI, Linköping, Sweden 1977

6. Strandberg L

Lateral Stability of Road Tankers. Volume I Main Report. Volume II Appendices. VTI Report No. 138A. VTI, Linköping, Sweden 1977

7. Nordmark S., Nordström 0.

Lateral Dynamics of Truck and Full Trailer Combinations. Paper presented at OECD symposium on Heavy Freight Vehicles and their Effects. Nov. 1977

8. Nordmark S., Nordström 0 .

Lane Change Dynamics versus Geometric Design of Truck and Full Trailer Combinations - a Computer Study. Paper presented at XVII FISITA Congress in Budapest 1978

9. Nordström 0., Nordmark S.

Test Procedures for the Evaluation of the Lateral Dynamics of Commercial Vehicle Combinations. Automobile Industrie No. 2, 1978

10. Nordström 0., Nordmark S. Handling Caracteristicts of Heavy Vehicle Combinations at Constant Speed. Final Report. (In Swedish) VTI Report No. 234. VTI, Linköping, Sweden 1981

11. Nordström 0 .

Antilock systems for heavy vehicles - State of the art, test methods and regulations. (Extensive Summary in English) VTI Report 257. VTI, Linköping, Sweden 1983

12. Palmkvist G., Nordström 0 . Hybrid Laboratory Test Method for Antilock Systems. The Dynamics of Vehicles on Roads and Railway Tracks. Proceedings 8th IAVSD-Symposium Cambridge Mass USA 1983. Swets \& Zeitlinger, Lisse, Holland

13. Nordst röm O., Ståhl P. Field testing of "double combinations" under winter conditions. STU Report. (In Swedish) VTI, Linköping, Sweden June 1984

14. Oppenheimer $P$.

The development of international antilock braking regulations. IMechE Conference on "Anti-lock braking systems for road vehicles" Paper C190/85. IMechE Conference Publications 1985-8. Mech Eng Publ Ltd. London 1985

15. Nordström 0 . Testing of antilock systems. Winter tests 
1985 for evaluation of draft revision of ECE

Reg. 13 Annex 13. (Extensive Summary in

English) VTI Report 304. VTI, Linköping,

Sweden 1986

16. ECE Regulation 13, Annex 13. Addendum 12 :

Regulation 13 to be annexed to the Agreement

Revision 2 - Amendment 3. Supplement 1 to the

05 series of amendments which entered into

force on 1 April 1987. E/ECE/324 Rev 1/Add

$12 /$ Rev 2/Amendment 3. United Nations, Geneva

1987

17. Nordström 0 .

Antilock system performance under winter

conditions-what should be required ? 11th ESV

Conference Washington DC May 12-15 1987

18. Nordström 0 .

Antilock Braking System Performance.

International Regulations Now and in the

Future - Some Swedish Viewpoints. Paper

presented at TRB - VTI Conference "Road and

Traffic Safety on Two Continents" 1987. VTI

Report 332A. VTI, Linköping, Sweden 1988

19. Nordström 0 .

Test methods and Requirements for ABS on Heavy Duty Trailers suited for Nordic Winter Conditions. (In Swedish) VTI Notat TF 50-10. VTI, Linköping, Sweden 1988

20. Palmkvist G.

Parallel Processor System for Real Time

Simulation. Automotive Simulation.

Proceedings of the 2nd European Cars/Trucks

Simulation Symposium Schliersee, FRG, May

1989. Springer-Verlag, Berlin, Heidelberg,

New York, London, Paris, Tokyo 1989

21. Strandberg L.

Braking Characteristics of 400 Heavy Trailer

Combinations from Denmark, Finland, Norway

and Sweden. 12th ESV Conference, Gothenburg, Sweden 1989 

Positions and opinions advanced in this paper are those of the author(s) and not necessarily those of SAE. The author is solely responsible for the content of the paper. A process is available by which discussions will be printed with the paper if it is published in SAE Transactions. For permission to publish this paper in full or in part, contact the SAE Publications Division.
Persons wishing to submit papers to be considered for presentation or publication through SAE should send the manuscript or a 300 word abstract of a proposed manuscript to: Secretary, Engineering Activity Board, SAE. 



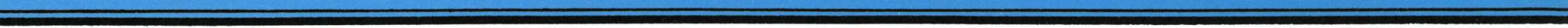

